\title{
Mass mortality of fish embryos in a lake ecosystem attributable to a flame retardant
}

\author{
Yu Li ${ }^{1}$, Kai Huang ${ }^{2}$, Jieqiong Jiang${ }^{1}$, Yue Xiao ${ }^{1}$, Lihui An ${ }^{3}$, Shiyi Zhang ${ }^{1}$, Qiyue Kang ${ }^{1}$, \\ Ruichao Chen ${ }^{1}$, Yingting Jia ${ }^{1}$, Xiaohua Zhang ${ }^{1}$, Chunsheng Liu ${ }^{2}$, and Jianying $\mathrm{Hu}^{1}$ \\ ${ }^{1}$ Peking University \\ ${ }^{2}$ Huazhong Agricultural University \\ ${ }^{3}$ Chinese Research Academy of Environmental Sciences
}

May 28, 2020

\begin{abstract}
Fishery resources are highly threatened by man-made chemicals that cause early life-stage mortality in fish, and could consequently block population recruitment. In a wide-scale and long-term investigation in Taihu Lake, we found that the temporal and spatial variation in embryonic mortality of crucian carp were consistent with the embryonic TDCIPP concentrations. We also confirmed in a well-controlled laboratory study that environmental concentrations of TDCIPP could cause embryonic mortality in crucian carp. Thus, TDCIPP was a major causal agent for mass embryonic mortality of crucian carp in Taihu Lake. These findings highlight the deleterious effect of this high-production-volume industrial chemical on global fishery and suggest ecosystem conservation should account for supervision of ubiquitous chemicals.
\end{abstract}

\section{Introduction}

Fisheries depletion has become a global problem and aroused attention for decades (Hutchings et al. 2000; Worm et al. 2016). Of 4,714 fisheries assessed in 2012 around the world, $68 \%$ have slipped below the biomass target that supports maximum sustainable yield (Worm et al. 2016), and some rivers and lakes even have experienced many local fishery collapses (Mcintyre et al. 2016). While invasive species and overfishing are usually proposed to be contributors, early life stage mortality of fish is also a factor, due to its effect on population maintenance. For example, mass hatchery stocking failed to re-establish self-sustaining lake trout populations in the Great Lakes, USA, partly due to the fact that $50 \%$ of offspring died at an early life-stage (Smith et al. 1994; Palace et al. 1998).

Several man-made chemicals, mainly organochlorines, have been associated with larval and adult mortality in wild fish (Smith et al. 1994; Palace et al. 1998; Hamilton et al. 2016; Sepúlveda et al. 2004). Notably, fish undergo a series of rapid cell divisions and differentiations during embryonic development, including largescale de novotranscription, and therefore fish embryos are much more sensitive to environmental pollutants than larval and adult fish (Mohammed et al. 2013; Cherr et al. 2017). Thus, organochlorines could cause embryonic mortality in wild fish and, over time, compromise natural population recruitment and ultimately induce fishery collapse. However, there is sparse evidence that widespread chemicals are lethal to embryos of wild fish since collecting fish embryo and tracking subsequent development are big challenges in aquatic ecosystems. Crucian carp (Carassius carassius) is ubiquitous in the lakes, rivers, and reservoirs, and therefore has been usually used as a bio-indicator of fish resources (Zheng et al. 2015). During the reproductive season, crucian carp spawns adhesive eggs over substrates such as shallow-shore aquatic macrophyte, where eggs remain until hatching (Shin-ichiro et al. 2011), facilitating large-sample-size egg collection and observation. 
Such reproduction feature of crucian carp give us a chance to observe whether a pollutant could cause embryo mortality.

Tris(1,3-dichloro-2-propyl) phosphate (TDCIPP), a chloro-organophosphorus flame retardant, is produced industrially in high volumes. TDCIPP has been reported to cause embryo mortality in a zebrafish embryo exposure ex vivo (Volz et al. 2016; Kupsco et al. 2017). Therefore, in the present study, we utilized reproductive characterization of crucian carp in natural population to address following questions. (i) Does mass mortality of crucian carp embryo occur in aqueous ecosystem? (ii) Is the embryonic mortality observed in field associated with embryonic TDCIPP concentration; (iii) Can TDCIPP at environmental levels cause the mass mortality of crucian carp embryos under controlled laboratory conditions? We performed mortality investigation and causal analyses by clarifying the temporal and spatial distributions of embryonic mortality and TDCIPP concentrations in crucian carp over three years in a lake ecosystem, and laboratory exposure experiments were also conducted to determine whether environmental concentrations of TDCIPP could cause embryonic mortality in crucian carp from natural population.

\section{Materials and Methods}

Embryo Collection in Taihu Lake. In 2016 and 2017, embryos of crucian carp were collected from water grass in SZ, GH, MIL and ZS (see Table S1 for location information) during the crucian carp reproduction season (April to May), with the permission of the fishery administration. Fingerling identification was based on the external characteristics and DNA barcode analysis, as described in Supporting Information (SI). After collection, embryos were transported to laboratory immediately with incubators at $18 \pm 2$, at which temperature crucian carp embryos developed slowly (Laurila et al. 1987), Then, the embryos were cultured until hatching in active carbon-treated drinking water $(1 \mathrm{~L}$ in $1.5 \mathrm{~L}$-glass dishes; each dish contained approximately 500 embryos) at $26+-1 \operatorname{deg} \mathrm{C}$ and under a $16 \mathrm{~h}: 8 \mathrm{~h}$ (light: dark) light cycle. The transport and culture conditions were identical for all sampling sites. In 2018, embryos were collected from GH and ZS by constructing artificial fish nests for locally tracking the developmental progress of crucian carp embryo. Artificial nest was made by fishing net by cutting into pieces and tied together to increase the area for crucian carp to spawn. Artificial nests were put into shallow water nearshore in GH and ZS according to a time schedule (Fig. $2 \mathrm{~A}$ and B), and five nests were used in each site.

Embryos from four sites in Taihu Lake were collected for TDCIPP analyzing prior to culture (approximately $50 \mathrm{mg}$ of embryos per sample; $\mathrm{n}=6$ ). The dead embryos and contemporaneous live embryos during culture were also sampled to determine TDCIPP concentrations [approximately $50 \mathrm{mg}$ of embryos per sample; $\mathrm{n}=$ 6 in 2017; $\mathrm{n}=3$ in 2018 (due to limited numbers of dead embryos)].

Exposure Experiment. One- to three-year old wild adult crucian carp including females and males, aged by measurement of dorsal spines and pectoral fin rays according to a previous study (Vilizzi et al. 2018), were captured from a natural population in October 2017, and then were exposed in a laboratory setting to TDCIPP for six months (October 2017-April 2018) at nominal concentrations of 8, 40, and $200 \mu \mathrm{g} / \mathrm{L}$. Exposure was conducted in 420-L glass tanks (30 fishes per tank, with each group containing three replicates) under a natural temperature and light cycle (to imitate the natural maturation of ovaries). The fish were fed on fish premix twice daily until the end of exposure. A flow-through system (Fig. S3) was used to renew the water daily, and water samples were collected monthly $(n=6)$ for TDCIPP analysis during the exposure period. After six months of exposure, embryos were obtained through artificial fertilization; a portion of these were sampled (approximately $50 \mathrm{mg}$ each sample, $\mathrm{n}=6$ ) for TDCIPP analysis and a portion were prepared for culture to enable study of embryonic development. Culture conditions of embryo and method for cell height quantification were according to a paper reported previously (Kupsco et al. 2017), and more details were provided in SI.

In April 2018, embryos were obtained from the adult crucian carp cultured in the control group in the exposure experiment as described above, and the larvae were exposed to TDCIPP from half-month-old (beginning eating) to sex maturation (June 2019) at nominal concentrations of 50, 500, 5000, and 50000 ng/L. Exposure was conducted in 420-L glass tanks (50 fishes per tank, each group containing three replicates) 
equipped with a flow-through system. During the exposure, water samples were collected quarterly $(\mathrm{n}=$ 5) for TDCIPP analysis. Fish were fed on live brine shrimp (Artemia nauplii) twice daily until fish were one-month-old, and then fed on fish premix twice daily until the end of exposure. After a one-year exposure, embryos were obtained through artificial fertilization, and samples were collected and developmental processes were observed according to the same method described above. After sample preparation, the TDCIPP concentrations in water and embryos were determined by liquid chromatography-tandem mass spectrometry (LC-MS/MS) analysis.

Chemical Analysis. All of the samples were collected in glass vials, with all vials having been pretreated in a muffle furnace at $450^{\circ} \mathrm{C}$ for $6 \mathrm{~h}$ to prevent contamination. Samples were frozen immediately at $-20^{\circ} \mathrm{C}$ after collection, and stored at this temperature until analysis.

Methods for sample preparation and TDCIPP quantification in water and embryo samples were according to our previous study with some modification (Zhao et al. 2018), and the details were provided in SI. TDCIPPd15 was used as the isotopic internal standard to correct the loss of TDCIPP during the sample preparation and to compensate for variations in LC-MS/MS instrumental response from injection to injection. Recoveries of TDCIPP in the water and embryo samples were $73.4 \pm 1.4 \%$ and $94.1 \pm 1.7 \%$, respectively. TDCIPP was detected in the procedural blanks at concentrations of $0.1 \pm 0.03 \mathrm{ng} / \mathrm{L}$ in water samples and $0.9 \pm$ $0.14 \mathrm{ng} / \mathrm{g}$ lw in embryo samples. The limits of quantitation (LOQs) were defined as 10 times the standard deviation of the procedural blanks, and thus the LOQ was $0.3 \mathrm{ng} / \mathrm{L}$ for water samples and $1.4 \mathrm{ng} / \mathrm{g} \mathrm{lw}$ for embryo samples. The final concentrations reported in this study were blank-subtracted, and all of the chemical analysis experiments were performed in triplicate.

Statistical Analyses. Differences in mortality and developmentally delayed rates of embryos from different sites in Taihu Lake were analyzed by the $\chi^{2}$ test. Concentrations of TDCIPP, mortality of embryos from the exposure experiment, and relative embryo height were analyzed by one-way analysis of variance (ANOVA) with Dunnett's test (95\% confidence interval). When the concentrations were below the LOQ, the values of the LOQs divided by 2 were used for calculation and statistical analysis. Differences were analyzed with SPSS (v22.0, IBM, Armonk, NY) and considered statistically significant at $p<0.05$.

\section{Results and Discussion}

Embryonic Mortality and TDCIPP Levels in Taihu Lake.Taihu Lake is the third largest freshwater lake and one of the most important freshwater fisheries in China (Guo et al. 2007). Unfortunately, Taihu Lake has been besieged by effluents of industrial wastewater, agricultural runoff, and domestic sewage for more than 30 years, which has generated great concern for the health of its fishery (Stone et al., 2011; Yang et al. 2008). In 2016, we collected crucian carp embryos from water grass in four sites of Taihu Lake (Fig. $1 \mathrm{~A}-\mathrm{B}$ ), and cultured these until hatching under well-controlled laboratory conditions. We found an obvious spatial distribution of crucian carp embryonic mortality in these samples (Fig. $1 \mathrm{C}$ ). The mortalities of crucian carp embryos in the northern areas of Taihu Lake [65.8\% (1249/1897) in Zhushan (ZS), $\chi^{2}=$ 900.5; $21.7 \%(205 / 944)$ in Meiliang (ML), $\chi^{2}=145.7$; and $15.2 \%(53 / 348)$ in Gonghu $\left.(\mathrm{GH}), \chi^{2}=70.6\right]$ were significantly $(p<0.001)$ greater than that in the eastern area $[2.2 \%(17 / 782)$ in Suzhou (SZ)], which was coincident with the distribution of reported TDCIPP concentrations in water and sediment of Taihu Lake (Cao et al. 2012; Zhao et al. 2018; Zhao et al. 2019). Since crucian carp in natural environment were exposed to multiple pathways and chemicals would undergo absorption, distribution, metabolism and excretion in vivo, internal exposure in embryo is much more suitable to interpret the lethal embryonic toxicity observed in crucian carp. In 2017, to clarify whether the high embryonic mortality observed in north Taihu Lake was related to TDCIPP pollution, we investigated association of crucian carp embryonic mortality with TDCIPP concentrations in crucian carp embryos across Taihu Lake. The mortality of embryos collected from ZS [38.8\% (435/1122)] was lower than that in 2016, but this was still substantially higher than the mortality of those from SZ [3.5\% (46/1304), $\chi 2=471.2, p<0.001$, Fig. $1 \mathrm{D}]$. The mortalities of embryos from another two northern sites $[6.9 \%(74 / 1075)$ for $\mathrm{GH}$ and $1.3 \%(12 / 944)$ for ML, Fig. $1 \mathrm{D}]$ were also less than those in 2016. In recent years, environmental pollution situation of the north area of Taihu Lake are improving, concomitant with strengthened environmental management, such as relocating hundreds 
of small chemical and manufacturing factories away from Taihu Lake and installing wastewater-treatment plants (Stone et al. 2011). It is surprising that TDCIPP concentrations in embryos of crucian carp from ZS $[104.2 \pm 4.8 \mathrm{ng} / \mathrm{g}$ of lipid weight $(\mathrm{lw})]$ were substantially $(p<0.001)$ higher than those from GH $(4.6 \pm$ $0.9 \mathrm{ng} / \mathrm{g} \mathrm{lw}), \mathrm{SZ}(4.1 \pm 1.2 \mathrm{ng} / \mathrm{g} \mathrm{lw})$, and ML $(1.8 \pm 0.5 \mathrm{ng} / \mathrm{g}$ of lw $)$ (Table 1), showing the similar spatial distribution with that of the mortality. This result suggested that TDCIPP could be a contributor to the high mortality of embryos observed in ZS. Benefit from the high mortality in ZS, we have a chance to collect enough number of dead embryos for analyzing TDCIPP in dead embryos. The concentration of TDCIPP in dead embryos $(134.5 \pm 8.1 \mathrm{ng} / \mathrm{g} \mathrm{lw})$ was 79.1 -fold higher than that in the live embryo $(1.7 \pm 0.9 \mathrm{ng} / \mathrm{g} \mathrm{lw})$ (Fig. S1 A), further supporting the causal role of TDCIPP in high embryo mortality.

In an effort to further improve the ecosystem in Taihu Lake, in 2017 the local government closed 779 chemical factories around Taihu Lake, and initiated $>1000$ key pollution-treatment projects in Taihu Lake, to last until 2018 (Jiangsu Government News 2018), thereby providing us with a good chance to obtain a temporal variation of pollution in the lake, and verify the correlation between TDCIPP concentration and embryonic mortality. Thus, crucian carp embryos were collected from ZS and GH in 2018, given that embryonic mortalities in these two sites were still relatively high in 2017 . We observed that decreasing embryonic TDCIPP concentrations $(17.1 \pm 3.0 \mathrm{ng} / \mathrm{g} \mathrm{lw}$ for $\mathrm{ZS}$ and $1.5 \pm 0.6 \mathrm{ng} / \mathrm{g} \mathrm{lw}$ for GH, Table 1) tracked with decreased embryonic mortality [4.0\% (48/1200) and 1.2\% (18/1480) in ZS and GH, respectively (Fig. $1 \mathrm{E}$ )], indicating that TDCIPP had been an important contributor to the mass mortality of crucian carp embryos observed in ZS in 2017 and 2018. Similar to what was observed in 2017, the concentrations of TDCIPP detected in dead embryos from GH $(70.5 \pm 24.1 \mathrm{ng} / \mathrm{g} \mathrm{lw})$ and ZS $(216.8 \pm 54.8 \mathrm{ng} / \mathrm{g} \mathrm{lw})$ were significantly higher $(p<0.05)$ than those in live embryos $(1.2 \pm 0.4 \mathrm{ng} / \mathrm{g}$ lw in GH and $10.5 \pm 5.3 \mathrm{ng} / \mathrm{g}$ lw in ZS, Fig. S1 B), further demonstrating our posited correlation mentioned above.

To develop a better understanding of the death of crucian carp embryos, we tracked embryonic development in 2018. We placed artificial fish nests into the lake at 16:00-17:00 one day during the reproductive season, and removed these at 08:00-09:00 the next day (Fig. 2 A and B), to ensure the collected embryos had been spawned on the same day. We then removed embryos from the nest at 09:00-11:00 of this same day [i.e., 0 days post-fertilization (dpf)], and inspected them to determine their developmental stage (11:00) (Fig. $2 \mathrm{C}$ and D). This inspection showed that at 11:00, the embryos of 1480 eggs from GH and 1200 from ZS were at the same developmental stage (Fig. $2 \mathrm{E}$ ); however, we found that there was an obvious delay in the subsequent development of embryos from ZS compared with those from GH. Specifically, embryos from GH started epiboly at 11:30, reached semi-epiboly at 13:30, and then completed epiboly at 17:30 (Fig. 2 F-I). The analogous times for embryos from ZS were 13:30, 15:30, and 19:30, respectively, showing a two-hour developmental delay in the embryos from ZS compared with those from GH (Fig. $2 \mathrm{~J}$ ). Moreover, this delay in embryos from ZS lasted throughout subsequent development (Fig. S2 A and B), and culminated in a significant increase in the unhatched rate at $2.5 \mathrm{dpf}$ (Fig. S2 C). In fish, epiboly of embryo begins at the gastrulation period, during which cells accumulate on the animal pole of the yolk and then spread over the surface. Normal cell migration is critical for subsequent development and ultimate survival of embryos (Kane et al. 1996), and TDCIPP has been reported to delay epiboly and cause embryonic death in zebrafish (Volz et al. 2016; Kupsco et al. 2017). Thus, the high embryonic mortality observed in embryos collected from ZS may have been a result of TDCIPP-perturbed epiboly in these embryos.

Crucian Carp from Natural Populations Exposed to TDCIPP. To further demonstrate that TDCIPP could delay embryonic development and induce embryonic mortality in crucian carp at environmentally observed concentrations, we collected adult crucian carp from natural populations, and exposed these fish to water containing three concentrations of TDCIPP: $2.7,8.1$, and $47.8 \mu \mathrm{g} / \mathrm{L}$, with $0.1 \%$ DMSO for six months (October 2017-March 2018). After exposure, dose-dependent TDCIPP concentrations were detectable in crucian carp embryos derived from the dosed fish, and the concentration $(73.6 \pm 6.3 \mathrm{ng} / \mathrm{g} \mathrm{lw})$ in the highest exposure group was lower than that found in wild crucian carp embryos from ZS in 2017 (Table 1). As these adult crucian carp were from a natural population, TDCIPP was also detectable in the embryos from the embryos derived from the control group. The cell heights above the yolk in embryos were measured at 6 hours post-fertilization (hpf) and $8 \mathrm{hpf}$, at the beginning of epiboly and at semi-epiboly time, respectively. The 
cell height at 6 hpf and 8 hpf significantly increased $1.12 \pm 0.02$ fold $(p<0.05)$ and $1.27 \pm 0.03$ fold $(p<$ 0.01) in the low TDCIPP exposure group, respectively, showing an obvious delay in development compared with the control group (Fig. 3 A-C). The validity of the delay effects observed at the low concentration was strengthened by the fact that similar effects were seen in higher-concentration treatments, in response to which cell heights above the yolk in embryos increased from $1.15 \pm 0.03$ to $1.16 \pm 0.04(p<0.01)$ fold at 6 hpf, and from $1.46 \pm 0.07$ to $2.19 \pm 0.13(p<0.01)$ fold at 8 hpf (Fig. $3 \mathrm{~B}$ and C). We also detected a strong lethal effect of TDCIPP on crucian carp embryos: embryonic mortalities increased in a dose-dependent manner and reached $51.3 \pm 9.7 \%(p<0.05)$ and $77.3 \pm 9.3 \%(p<0.01)$ in high-concentration exposure groups, which were significantly higher than that in the low-concentration exposure group $(42.3 \pm 4.1 \%)$ and the control $(37.0 \pm 2.1 \%)$ (Fig. $3 \mathrm{D})$. The fact that TDCIPP accumulated in crucian carp embryos at concentrations lower than those detected in ZS showed that the mass mortality observed in ZS was at least partly induced by TDCIPP. The concentration accumulated in embryos during the exposure was not great, and the higher mortality observed in the laboratory than in the wild may be attributable to the complex exposure situation in the wild. However, TDCIPP was also detected in the control group after exposure, indicating that environmental chemical residues may remain in the ovaries of adult crucian carp directly captured from the natural population. Other chemicals may also accumulate in the fish, and thus the magnitude of the role of TDCIPP in inducing embryonic delay and mortality remains to be quantified.

To remove the influence of the "background" pollution described above, and thus obtain accurate data supporting that TDCIPP at environmental concentration could induce crucian carp embryo mortality, we obtained offspring of adult crucian carp from the control group in the above experiment during April 2018, and further exposed these fish to environmental levels of TDCIPP until they reached sexual maturity (June 2019). After this nearly 14-month exposure, we were unable to detect TDCIPP in the embryos from the control fish, but TDCIPP was detected in embryos from all exposure groups, at concentrations from $2.2 \pm 0.7$ to $37.1 \pm 22.5 \mathrm{ng} / \mathrm{g} \mathrm{lw}$ (Table 1), which overlapped with the concentrations of TDCIPP detected in embryos from Taihu Lake. We again observed developmental delays in the exposure groups that were ascribable to TDCIPP, with the cell height above the yolk of embryos increasing significantly in a dose-dependent manner at both 6 hpf $[1.07(p>0.05)$ to $1.33(p<0.01)$ fold] and 8 hpf $[1.18(p<0.05)$ to $2.46(p<0.01)$ fold] (Fig. $4 \mathrm{~B}$ and $\mathrm{C}$ ). Mortality also increased in all exposure groups $[7.0 \pm 1.1-33.3 \pm 3.1 \%$ compared with the control $(6.3 \pm 0.5 \%)$, Fig. $4 \mathrm{D}]$, demonstrating the toxicity of TDCIPP to embryonic development. The lowest observed effective concentration (LOEC) was $174.6 \mathrm{ng} / \mathrm{L}$, exposure to which resulted in an embryonic TDCIPP concentration of $10.0 \mathrm{ng} / \mathrm{g} \mathrm{lw}$, lower than that $(17.1 \pm 3.0 \mathrm{ng} / \mathrm{g}$ lw) detected in wild crucian carp embryos from ZS in 2018 and much lower than that $(104.2 \pm 4.8 \mathrm{ng} / \mathrm{g} \mathrm{lw})$ detected in embryos from ZS in 2017.

Taken together, we consider that these multiple lines of evidence strongly suggest that TDCIPP is an important causal agent for the mortality of crucian carp embryos in Taihu Lake. Although the pollution situation of TDCIPP in Taihu Lake has been improved in recent years, TDCIPP is ubiquitous in surface waters and fishes worldwide; its natural aquatic concentrations have been quantified as up to $149 \mathrm{ng} / \mathrm{L}$ in England (Cristale et al. 2013a), $200 \mathrm{ng} / \mathrm{L}$ in Spain (Cristale et al. 2013b), $378 \mathrm{ng} / \mathrm{L}$ in China (Hu et al. 2014), $450 \mathrm{ng} / \mathrm{L}$ in the USA (Sutton et al. 2019), $678 \mathrm{ng} / \mathrm{L}$ in Italy (Bacaloni et al. 2008), and its body concentrations in wild fish have been quantified as $9.6 \mathrm{ng} / \mathrm{g} \mathrm{lw}$ in the USA and Norway (Guo et al. 2017; Ingeborg et al. 2015), up to $140 \mathrm{ng} / \mathrm{g} \mathrm{lw}$ in Sweden (Sundkvist et al. 2010), and $251 \mathrm{ng} / \mathrm{g}$ lw in China (Ma et al. 2013). Such concentrations were similar or even much higher than the threshold TDCIPP concentrations above which we observed embryonic mortality in this study. Mechanistically, TDCIPP may have epigenetic effects on development via altering DNA methylation reprogramming (Volz et al. 2016; Kupsco et al. 2017), the correct format of which is critical for key early events and later differentiation during embryonic development of various animal species (Volz et al. 2016; Stancheva et al. 2002; Smith et al. 2012; Guo et al. 2014). Thus, TDCIPP may have globally significant deleterious effects on fish population recruitment, contributing to worldwide depletion of fisheries. Thus far, TDCIPP has been only banned for use in childcare products in the USA, due to its developmental and neural toxicity (U. S. EPA 2015). The worldwide production and consumption of TDCIPP remains high, with annually manufactured/imported 
volumes being 2000-20000 tons in Europe (ECHA) and 23000 tons in China (based on data from the National Chemistry Registry Center), and annual consumption in the USA being 2435 tons (U. S. EPA 2014). Our results have unambiguously highlighted the negative effects of TDCIPP on worldwide fisheries and fish population maintenance, and therefore conservation of ecosystem should account for supervision of ubiquitous chemicals.

\section{Acknowledgements}

We thank Mr. Jianming Lu and Mr. Zhenglin Yang from Taihu Fishery Management Committee, Jiangsu, China, for assistance with investigation in Taihu Lake. This work is supported by the National Natural Science Foundation of China [41821005, 41330637, and 21622702].

\section{References}

1. Bacaloni, A., et al. (2008). Occurrence of organophosphorus flame retardant and plasticizers in three volcanic lakes of Central Italy. Environ. Sci. Techno.l42, 1898-1903.

2. Cao, S. et al., (2012). Levels and distributions of organophosphate flame retardants and plasticizers in sediment from Taihu Lake, China.Environ. Toxicol. Chem. 31, 1478-1484.

3. Cherr, G. N., Fairbairn, E., Whitehead, A. (2017). Impacts of petroleum-derived pollutants on fish development. Ann. Rev. Anim. Biosci. 5(1) , 185-203.

4. Cristale, J., Katsoyiannis, A., Sweetman, A. J., et al. (2013a). Occurrence and risk assessment of organophosphorus and brominated flame retardants in the River Aire (UK). Environ. Pollut. 179 , 194-200.

5. Cristale, J., Lacorte, S. (2013b). Development and validation of a multiresidue method for the analysis of polybrominated diphenyl ethers, new brominated and organophosphorus flame retardants in sediment, sludge and dust. J. Chromatogr. A. 1305, 267-275.

6. European Chemicals Agency (ECHA), https://echa.europa.eu/substance-information//substanceinfo/100.033.767

7. Guo, H., et al. (2014). The DNA methylation landscape of human early embryos. Nature 511 , 606-610.

8. Guo, J. Venier, M. Salamova, A., et al. (2017). Bioaccumulation of dechloranes, organophosphate esters, and other flame retardants in great lakes fish. Sci. Total. Environ. 583 , 1-9.

9. Guo, L. (2007). Doing battle with the green monster of Taihu lake.Science 317, 1166.

10. Hamilton, P. B., et al. (2016). Population level consequences for wild fish exposed to sublethal concentrations of chemicals-a critical review. Fish Fish. 17, 545-566.

11. $\mathrm{Hu}, \mathrm{M}$., et al. (2014). Regional distribution of halogenated organophosphate flame retardants in seawater samples from three coastal cities in China. Mar. Pollut. Bull. 86 , 569-574.

12. Hutchings, J. A. (2000). Collapse and recovery of marine fishes. Nature 406 , 882.

13. Ingeborg, G., et al. (2015). Organophosphorous flame retardants in biota from Svalbard, Norway. Mar. Pollut. Bull.101(1), 442-447.

14. Jiangsu Government News. Available at http://www.jiangsu.gov.cn/art/2018/10/17/art_60096_ 7842897.html (2018).

15. Kane, D. A., et al. (1996). The zebrafish epiboly mutants.Development 123, 47-55.

16. Kupsco, A., Dasgupta, S., Nguyen, C., et al. (2017). Dynamic alterations in DNA methylation precede tris(1,3-dichloro-2-propyl) phosphate-induced delays in zebrafish epiboly. Environ. Sci. Technol. Lett. $4,367-373$.

17. Ma, Y. Q., et al. (2013). Microwave-assisted extraction combined with gel permeation chromatography and silica gel cleanup followed by gas chromatography-mass spectrometry for the determination of organophosphorus flame retardants and plasticizers in biological samples. Anal. Chim. Acta. $\mathbf{7 8 6}$, 47-53.

18. Mcintyre, P. B. C., Liermann, A. R., Revenga, C. (2016). Linking freshwater fishery management to global food security and biodiversity conservation. P. Natl. Acad. Sci. U. S. A. $113,12880-12885$.

19. Mohammed, A. (2013) "Why are early life stages of aquatic organisms more sensitive to toxicants than 
adults?" in New insights into toxicity and drug testing, pp. 49-62.

20. Laurila, S., Piironen, J., Holopainen, I. J. (1987). Notes on egg development and larval and juvenile growth of crucian carp (Carassius carassius (L)). Ann. Zool. Fenn. 24 , 315-321.

21. Palace, V. P., et al. (1998). An evaluation of the relationships among oxidative stress, antioxidant vitamins and early mortality syndrome (EMS) of lake trout (Salvelinus namaycush) from Lake Ontario.Aquat. Toxicol. 43 , 195-208.

22. Sepulveda, M. S., et al. (2004). Organochlorine pesticides and thiamine in eggs of largemouth bass and American alligators and their relationship with early life-stage mortality. J. Wildlife Dis.40 , 782-786.

23. Shin-ichiro, S. M. Terui, A, Kodama, K., et al. (2011). Influence of connectivity, habitat quality and invasive species on egg and larval distributions and local abundance of crucian carp in Japanese agricultural landscapes. Biol. Conserv. $144,2081-2087$.

24. Smith, I. R., Marchant, B., Heuvel, M. R., et al. (1994). Embryonic mortality, bioassay derived 2,3,7,8tetrachlorodibenzo-p-dioxin equivalents, and organochlorine contaminants in Pacific Salmon from Lake Ontario. J. Great Lakes Res. 20, 497-509.

25. Smith, Z. D., et al. (2012). A unique regulatory phase of DNA methylation in the early mammalian embryo. Nature 484, 339-344.

26. Stancheva, I., EI-Maarri, O., Walter, J., et al. (2002). DNA methylation at promoter regions regulates the timing of gene activation in Xenopus laevis embryos. Dev. Biol. $243,155-165$.

27. Stone, R. (2011). China aims to turn tide against toxic lake pollution. Science 333, 1210-1211.

28. Sundkvist, A. M., Olofssona, U., Haglunda, P. (2010). Organophosphorus flame retardants and plasticizers in marine and fresh water biota and in human milk. J Environ Monit 12, 943-951.

29. Sutton, R. Chen, D., Sun, J., et al. (2019). Characterization of brominated, chlorinated, and phosphate flame retardants in San Francisco Bay, an urban estuary. Sci. Total. Environ.652 , 212-223.

30. U. S. Environmental Protection Agency (EPA), 744-R-15e1002 (2015).

31. U. S. Environmental Protection Agency (EPA) "Chemical Data Reporting (2014)". https://comptox. epa.gov/dashboard/dsstoxdb/results?search=DTXSID9026261\#production-volume.

32. Vilizzi, L. (2018). Age determination in common carp Cyprinus carpio : history, relative utility of ageing structures, precision and accuracy. Rev. Fish. Biol. Fisher. 28(3) , 461-484.

33. Volz, D. C., et al. (2016). Tris(1,3-dichloro-2-propyl) phosphate induces genome-wide hypomethylation within early zebrafish embryos.Environ. Sci. Technol. 5 , 10255-10263.

34. Worm, B. (2016). Averting a global fisheries disaster. P. Natl. Acad. Sci. U. S. A. 113 , 4895-4897.

35. Yang, M., et al. (2008). Taihu Lake not to blame for Wuxi's woes.Science 319, 158-158.

36. Zhao, H. Q., et al. (2018). Trophic transfer of organophosphorus flame retardants in a lake food web. Environ. Pollut . 242, 1887-1893.

37. Zhao, H. Q., et al. (2019). Occurrence, Bioaccumulation, and Trophic Transfer of Oligomeric Organophosphorus. Flame Retardants in an Aquatic Environment. Environ. Sci. Technol. Lett. $6,323-328$.

38. Zheng, B., Liu, R., Liu, Y., et al. (2015). Phenolic endocrine-disrupting chemicals and intersex in wild crucian carp from Hun River, China. Chemosphere 120, 743-749.

Table 1. Concentrations of TDCIPP in embryos from different bays in Taihu Lake and in water during exposure period and embryos after exposure.

\begin{tabular}{|c|c|c|c|c|c|c|c|c|}
\hline \multirow[b]{2}{*}{ Site } & $\begin{array}{l}\text { Will } \\
\text { inve } \\
\text { Site }\end{array}$ & \multicolumn{3}{|c|}{$\begin{array}{l}\text { Wild } \quad \text { Wild } \\
\text { tiomvestigatiömestigation }\end{array}$} & & \multicolumn{3}{|c|}{$\begin{array}{l}\text { Laborator£aborator£aborator£aborator } \\
\text { exposure exposure exposure exposure }\end{array}$} \\
\hline & Site & $\begin{array}{l}\text { Embryo } \\
\text { (ng/g } \\
\text { lw) }\end{array}$ & $\begin{array}{l}\text { Embryo } \\
\text { (ng/g } \\
\mathrm{lw})\end{array}$ & $\begin{array}{l}\text { Embryo } \\
\text { (ng/g } \\
\text { lw) }\end{array}$ & $\begin{array}{l}\text { Water } \\
(\mu \mathrm{g} / \mathrm{L})\end{array}$ & $\begin{array}{l}\text { Water } \\
(\mu \mathrm{g} / \mathrm{L})\end{array}$ & $\begin{array}{l}\text { Embryo } \\
\text { (ng/g } \\
\text { lw) }\end{array}$ & $\begin{array}{l}\text { Water } \\
(\mathrm{ng} / \mathrm{L})\end{array}$ \\
\hline & & $2017^{\mathrm{a}}$ & $2018^{\mathrm{b}}$ & $2018^{\mathrm{b}}$ & $2018^{\mathrm{c}}$ & $2018^{\mathrm{c}}$ & $2018^{\mathrm{c}}$ & $2019^{\mathrm{d}}$ \\
\hline SZ & SZ & $\begin{array}{l}4.1 \pm \\
1.2 \\
\text { ND-9.5 }\end{array}$ & & & 0 & 0 & $\begin{array}{l}44.3 \pm \\
1.7\end{array}$ & 0 \\
\hline
\end{tabular}




\begin{tabular}{|c|c|c|c|c|c|c|c|c|}
\hline & $\begin{array}{l}\text { Wild } \\
\text { inves } \\
\text { GH }\end{array}$ & \multicolumn{3}{|c|}{$\begin{array}{l}\text { Wild Wild } \\
\text { tiomvestigatiomvestigation }\end{array}$} & & \multicolumn{3}{|c|}{$\begin{array}{l}\text { Laborator£aborator£aborator£aborator } \\
\text { exposure exposure exposure exposure }\end{array}$} \\
\hline $\mathrm{GH}$ & $\mathrm{GH}$ & $\begin{array}{l}4.6 \pm \\
0.9 \\
2.4-8.0\end{array}$ & $\begin{array}{l}1.5 \pm \\
0.6 \\
\text { ND-2.9 }\end{array}$ & $\begin{array}{l}1.5 \pm \\
0.6 \\
\text { ND-2.9 }\end{array}$ & 2.7 & 2.7 & $\begin{array}{l}46.1 \pm \\
2.8\end{array}$ & 4.9 \\
\hline ML & ML & $\begin{array}{l}1.8 \pm \\
0.5 \\
\text { ND-4.2 }\end{array}$ & & & 8.1 & 8.1 & $\begin{array}{l}52.9 \pm \\
3.2\end{array}$ & 174.6 \\
\hline ZS & ZS & $\begin{array}{l}104.2 \\
\pm 4.8 \\
86.5- \\
114.5\end{array}$ & $\begin{array}{l}17.1 \pm \\
2.4 \\
14.0- \\
23.1\end{array}$ & $\begin{array}{l}17.1 \pm \\
2.4 \\
14.0- \\
23.1\end{array}$ & 47.8 & 47.8 & $\begin{array}{l}73.6 \pm \\
6.3\end{array}$ & 617.5 \\
\hline
\end{tabular}

${ }^{\mathrm{ab}}$ Data were presented with mean \pm standard error, and range, $\mathrm{n}=6$; ${ }^{\mathrm{c}}$ Data of water were presented with average, $\mathrm{n}=6$; Data of embryo were presented with mean \pm standard error, $\mathrm{n}=6$; ${ }^{\mathrm{d}}$ Data of water were presented with average, $\mathrm{n}=5$; Data of embryo were presented with mean \pm standard error, $\mathrm{n}=6$.

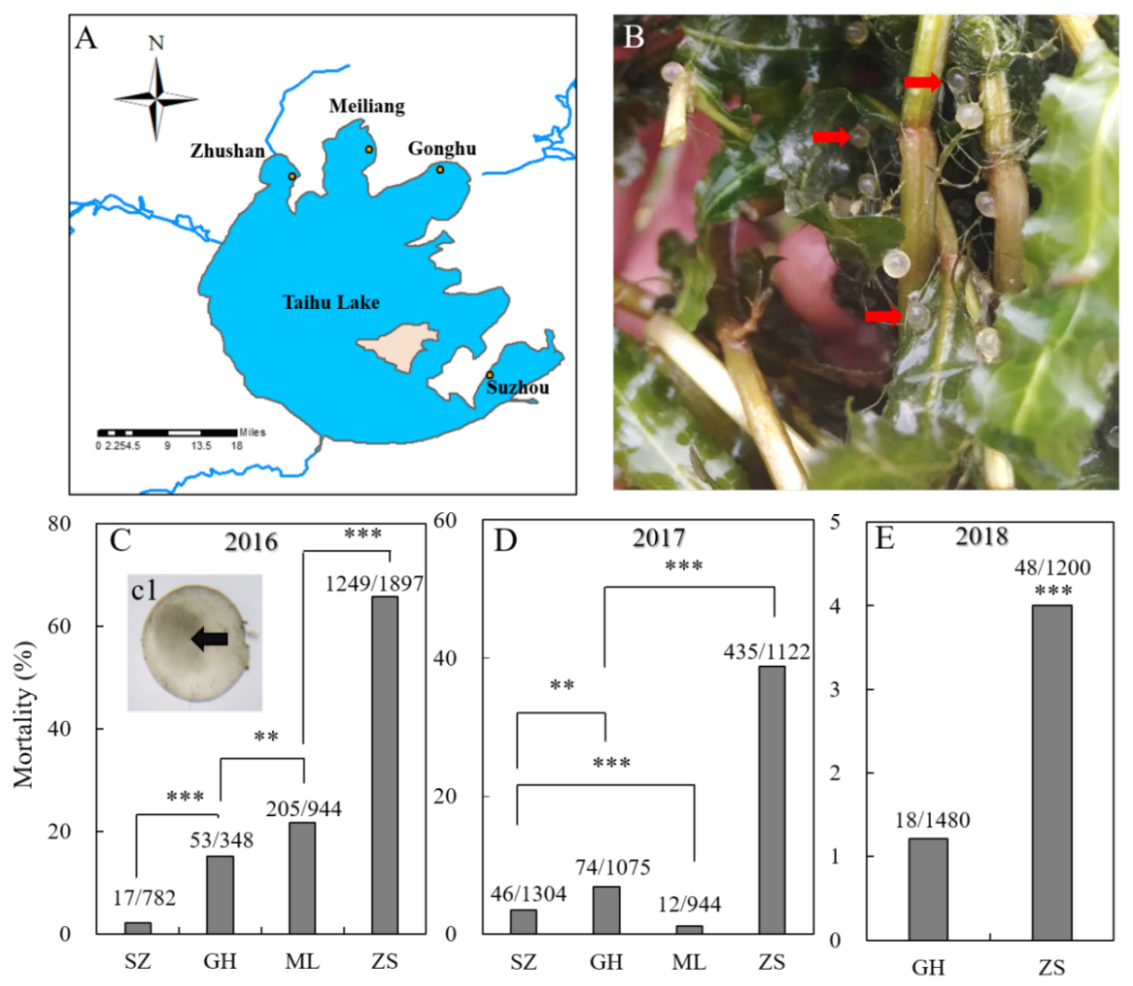

Figure 1. Field observation of embryonic mortality. (A) Sampling sites in Taihu Lake; (B) Embryo collected by water grass, red arrow point to crucian carp embryo; (C-E) Embryonic mortality in different sites from 2016-2018; (c1) Dead embryo, black arrow point to dead cell mass. ${ }^{* *} p<0.01,{ }^{* * *} p<0.001$. 


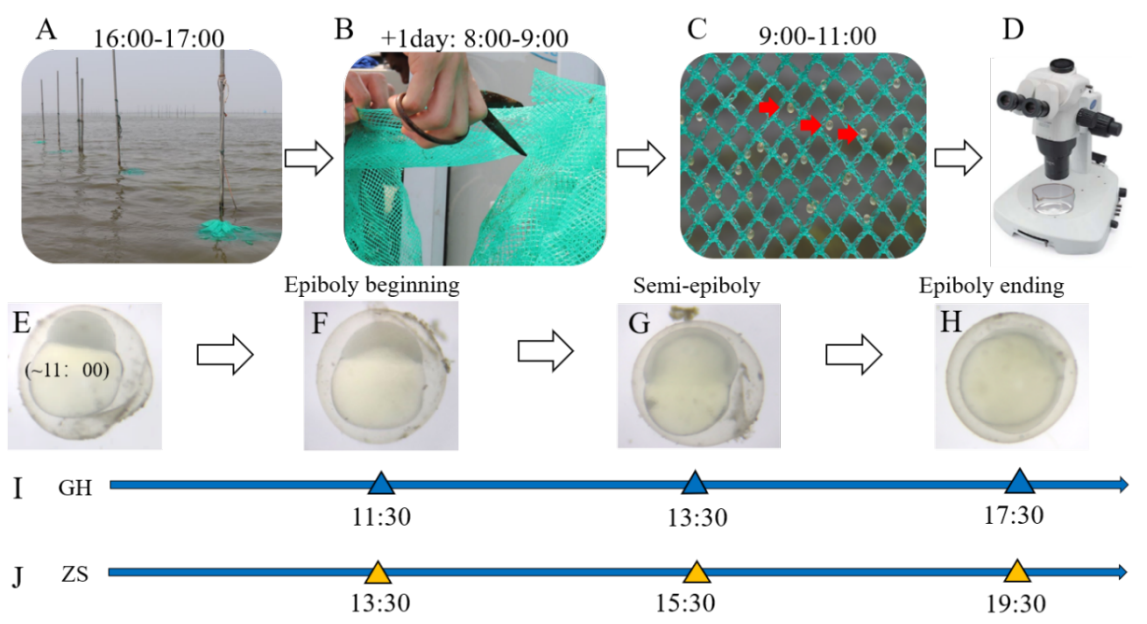

Figure 2. Embryo development tracking by constructing artificial nest in ZS and GH bays in 2018. (A) Artificial fish nests were set in water at 16:00-17:00; (B) Artificial fish nests with fish embryo were cut off at the next morning (8:00-9:00); (C) Embryos were removed from the artificial fish nest within two hours (9:00-11:00); (D) Development progresses of embryos were observed by microscope; (E) Embryos collected from GH and ZS in 2018 at 11:00; (F) Embryo begins epiboly; (G) Embryo reaches semi-epiboly; (H) Embryo completes epiboly; and early developmental time scheme of embryos from GH (I) and ZS (J).

\begin{tabular}{|c|c|c|c|c|}
\hline $\mathrm{A}$ & Control & $2.8 \mu \mathrm{g} / \mathrm{L}$ & $8.1 \mu \mathrm{g} / \mathrm{L}$ & $47.8 \mu \mathrm{g} / \mathrm{L}$ \\
\hline $6 \mathrm{hpf}$ & & & & \\
& & & & \\
\hline $8 \mathrm{hpf}$ & & & & \\
& & & & \\
& & & & \\
\hline
\end{tabular}
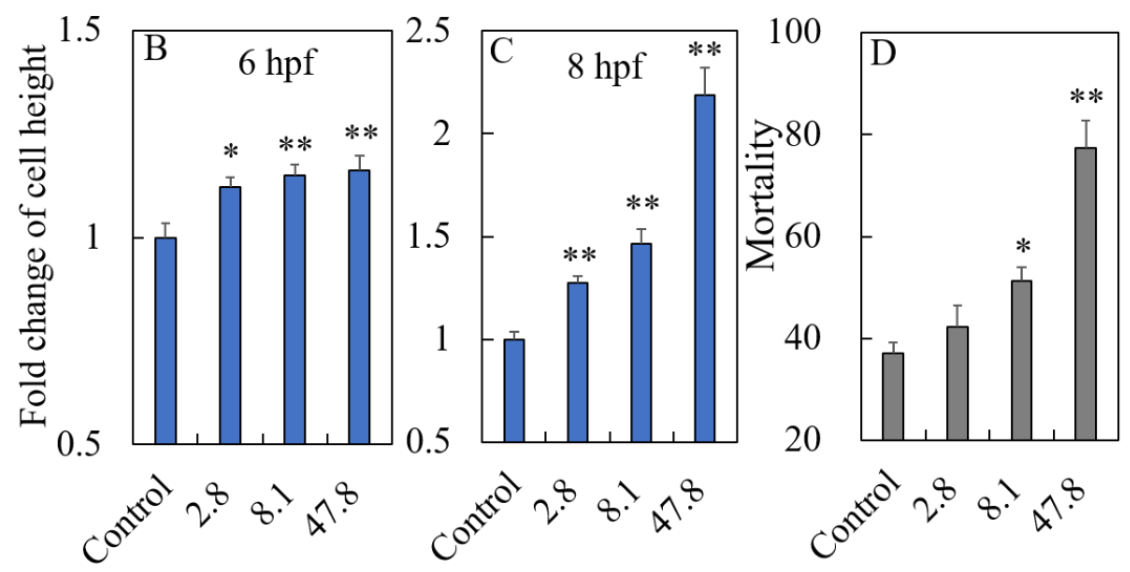

TDCPP Concentration $(\mu \mathrm{g} / \mathrm{L})$ 
Figure 3. TDCIPP delayed development and induced high mortality of crucian carp embryo. The embryos were spawned by crucian carp (from natural population) exposed to TDCIPP for 6 months. (A) Representative images of epiboly in different groups at 6 and 8 hpf; (B-C) Relative cell height at 6 hpf and 8 hpf; (D) Mortality of embryo after TDCIPP exposure. ${ }^{*} p<0.05,{ }^{* *} p<0.01$.
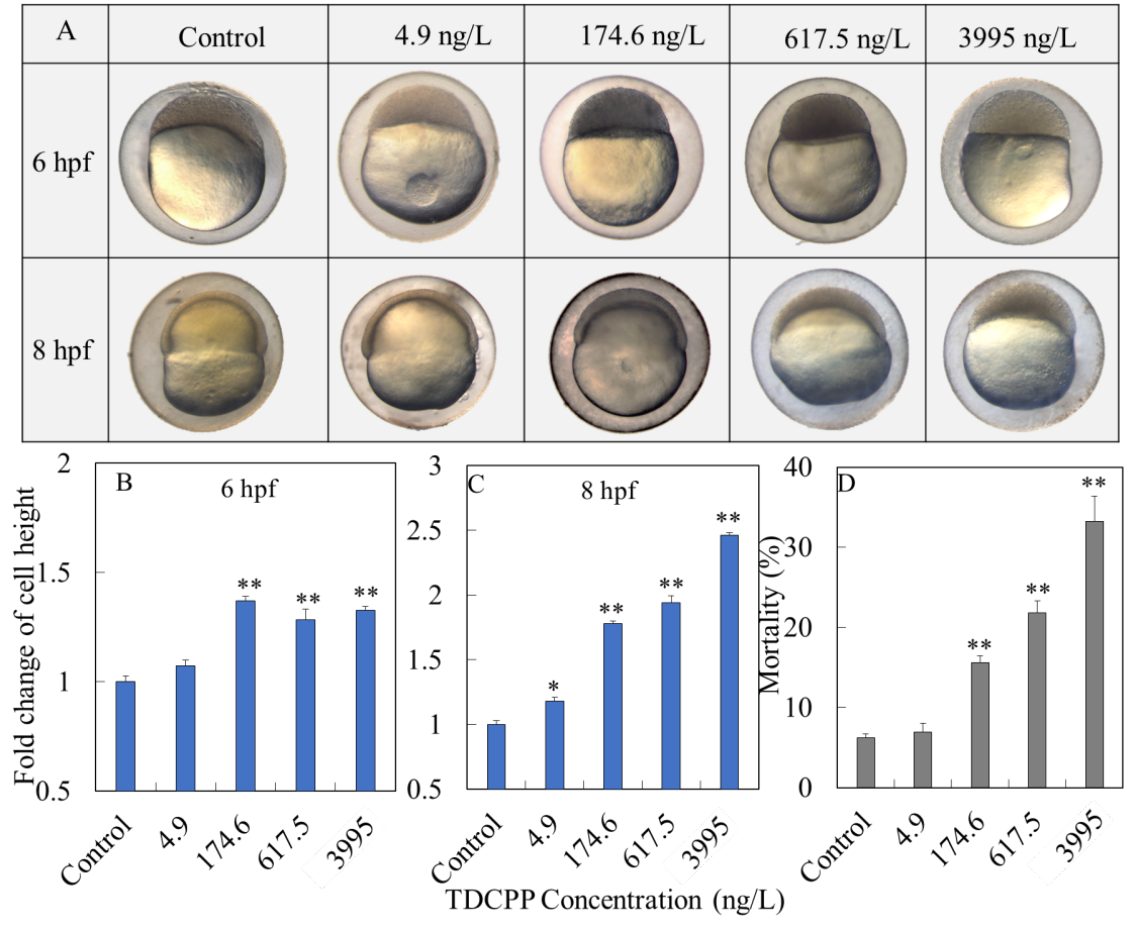

Figure 4. TDCIPP delayed development and induced high mortality of crucian carp embryo. The embryos were spawned by crucian carp (offspring of control group) exposed to TDCIPP for 14 months. (A) Representative images of epiboly in different groups at 6 and $8 \mathrm{hpf}$; (B-C) Relative cell height at $6 \mathrm{hpf}$ and $8 \mathrm{hpf}$; (D) Mortality of embryo after TDCIPP exposure. ${ }^{*} p<0.05,{ }^{* *} p<0.01$. Graphic Abstract

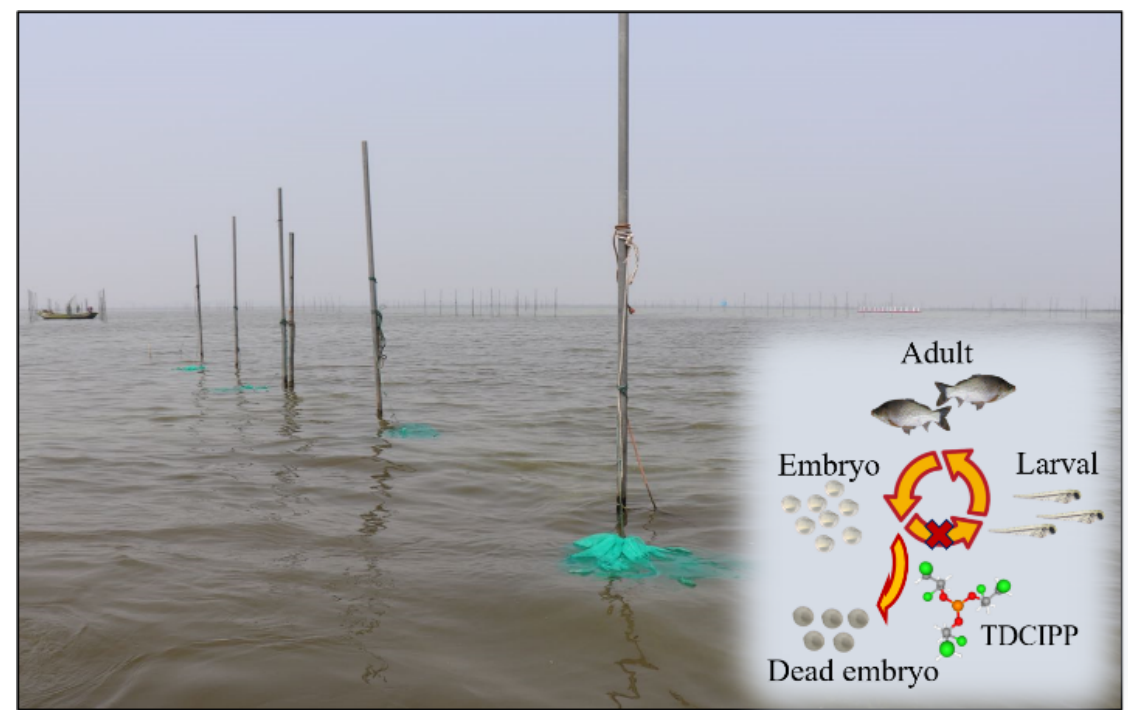

